\title{
Talk the talk and walk the walk! Association between Weekly Exercise Load and Knowledge about Recommendations for Fighting Innactivity
}

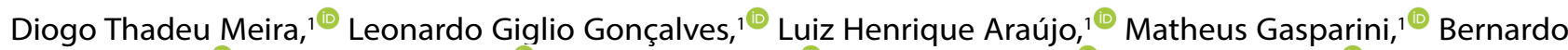
Souza Cunha, ${ }^{1 \oplus}$ Amanda Monteiro, ${ }^{2 \oplus}$ Michele Heringer, ${ }^{1 \oplus}$ Christiane Prado, $^{2 \oplus}$ Andre Volschan, ${ }^{3 \oplus}$ Fabrício Braga da Silva ${ }^{1,2}$

Casa de Saúde São José, Rio de Janeiro, RJ - Brazil

Laboratório de Performance Humana, ${ }^{2}$ Rio de Janeiro, RJ - Brazil

Hospital Pró-Cardíaco, ${ }^{3}$ Rio de Janeiro, RJ - Brazil

\section{Abstract}

Background: The World Health Organization (WHO) recommends as a weekly "target dose" of exercise 150 minutes of moderate exercise or 75 minutes of intense exercise. Public health policies have prioritized the practice of exercise as a strategy for disease prevention and health promotion, with health professionals as their main promoters.

Objective: To assess the interaction between the amount of exercise per week and the knowledge about recommendations for fighting a sedentary lifestyle among health care professionals attending a congress of cardiology.

Methods: Participants of the 2017 Rio de Janeiro Society of Cardiology Congress were interviewed. Knowledge about the World Health Organization (WHO) recommendations for fighting a sedentary lifestyle was assessed by asking participants the question: "How much weekly exercise is recommended by the WHO?" Responders were stratified by the weekly exercise load reported. A multivariate logistic model was created to determine independent predictors of knowledge.

Results: A total of 426 participants were interviewed (45.5\% men, median age 31 years, 37.8\% physicians, $65.8 \%$ of the physicians were cardiologists). The overall knowledge level was $44.6 \% ; 38.1 \%, 52.7 \%$ and $56.6 \%$ among nonphysicians, non-cardiologists and cardiologists, respectively $(\mathrm{p}=0.002)$. Of all participants, $21.8 \%$ were inactive, $15 \%$ were lightly active, $34.7 \%$ moderately active and $28.4 \%$ highly active, and the percentage of individuals who gave a correct answer to the question on exercise recommendations was $30.1 \%, 42 \%, 48 \%$ and $52.9 \%$ respectively $(\mathrm{p}<0.0001)$. In the multivariate analysis, being highly active ( $\mathrm{OR}=2.25, \mathrm{IC} 95 \%, 1.238-4.089)$, moderately active (OR $=1.93$, IC $95 \% 1.105$ - 3.39) and being a cardiologist (OR = 2.01, IC 95\% $1.243-3,267)$ were predictors of knowledge.

Conclusions: There was a linear association between exercise level and knowledge about the WHO recommendations on exercise. Policies to stimulate the practice of exercise among health professionals can positively impact campaigns for reducing sedentary lifestyle in the general population. (Int J Cardiovasc Sci. 2019;32(5):473-480)

Keywords: Cardiovascular Diseases/prevention and control; Exercise; Sports; Sports Medicine/trends; Health Promotion, Preventive Medicine; Physical Fitness.

\section{Introduction}

According to the World Health Organization (WHO), approximately 17.5 million people die of cardiovascular diseases every year. A considerable number of them have unhealthy habits, including a sedentary lifestyle, which accounts for more than 5 million deaths per year and an annual cost of 67.5 billion dollars. ${ }^{1-3}$

Data from VIGITEL (an epidemiological study conducted by the Health Surveillance Agency every year in Brazil), ${ }^{4}$ show that $52.4 \%$ of Brazilians do not practice exercise in their free time. On the "Practice of 
Sports and Physical Activity" supplement of the 2015 National Household Sample Survey (PNAD), 100 million Brazilians were not engaged in the practice of any sports, ${ }^{5}$ and in Sao Paulo, 69.3\% of individuals aged between 15 and 59 years is sedentary.

The WHO recommends at least 150 minutes of moderate-intensity or at least 75 minutes of vigorousintensity aerobic physical activity throughout the week, or any combination of these. This recommendation is adopted by the Brazilian Society of Cardiology.

Patra et al., ${ }^{6}$ observed that better habits of physical exercise among physicians were associated with better patient counseling on this practice. Physically active physicians were three times more likely to regularly promote and advise their patients on physical activity. Of the146 professionals interviewed, $62 \%$ reported to be inactive. The main barriers to physical activity were reported to be lack of time, lack of motivation, and being too tired, and half of them $(51.4 \%)$ reported to be familiar with the WHO recommendations on physical activity.

Recently, the American Heart Association, in a "call to action" for a National Physical Activity Plan, highlighted that counseling of health care professionals has a significant effect on adoption of healthy behaviors, including regular exercise, which is one of the most powerful strategies for health promotion that physicians and other health care professionals can recommend to patients. ${ }^{7}$

The objectives of the study were 1) to evaluate whether knowledge about the WHO recommendations was greater among physically active individuals; 2 ) and if there is a relationship between this knowledge and the fact of being (or not) a cardiologist physician.

\section{Methods}

During the Rio de Janeiro Society of Cardiology Congress held in Rio de Janeiro, Brazil between April 14 and 16, 2017, attendees were randomly approached by interviewers (a fifth-year medical school student or a physical educator, previously trained by a cardiologist) and invited to answer an interview question and a structured self-administered questionnaire. Data were collected during the three days of the meeting, during the breaks between the lecturers.

The first part (interview) consisted of one question with five alternatives: "How much weekly exercise is recommended by the WHO?"8,9 The correct answer, according to the $\mathrm{WHO}$ and to the Brazilian Society of Cardiology guidelines, was 150 minutes of moderateintensity or 75 minutes of vigorous-intensity exercise. All other alternative answers presented different amounts of exercise. At the second phase, a self-administered questionnaire was administered to quantify the amount of exercise practiced by the volunteer. This questionnaire was composed of three closed questions about frequency, intensity and duration of exercise. Each answer was assigned a point value, which was computed for the Physical Activity Summary Index (PA-I).$^{10}$ At this phase, participants also reported their body weight and height for body mass index (BMI) calculation, and age in years. The answers to both questionnaires were sent to a database via an online form.

Following the interview and the questionnaire, volunteers had their heart rate measured using a digital oximeter (MeasuPro Instant Read Digital Pulse Oximeter ${ }^{\circledR}$ ) while resting in standing position for three minutes. Heart rate was measured preferentially from the right index finger, with elbow flexed to 90 degrees, with an expected error of $\pm 3 \mathrm{bpm}$ according to manufacturer's specifications. Each measurement should have lasted at least 10 seconds, and had a high signal quality, defined as a high-amplitude pulse oximetry wave on the oximeter display. Heart rate measurements were repeated two minutes later in case of values greater than 90 beats per minute.

PA-I, BMI, age and heart rate were used for $\mathrm{VO}_{2} \max$ estimation using the formula proposed by Kurtze et al., ${ }^{11}$ This formula has been used in the World Fitness Study (https:// www.worldfitnesslevel.org), ${ }^{12}$ a project of the European Society of Cardiology, from which the values predicted for each age within the range between 20 and 90 years were derived.

Volunteers were classified as inactive, lightly active, moderately active, and highly active based on PA-I values, as proposed by Apenes et al., ${ }^{10}$ who showed the high reliability of this index. A PA-I of $0.05-1.50$ indicated lightly active, a PA-I of 1.51-3.75 moderately active, and a PA-I of 3.76 - 15.00 highly active. The percentage of correct answers to the question "How much weekly exercise is recommended by the WHO?" was compared by level of physical activity, i.e., by the presence or not of a poor aerobic conditioning (lower than $80 \%$ of predicted by age and sex) and occupation, which was stratified in non-physicians, cardiologists, and non-cardiologist physicians. Besides, the percentage of $\mathrm{VO}_{2}$ predicted by age was compared between volunteers 
who answered the question correctly and those who gave a wrong answer.

The sample size was defined for a percentage of correct answers of 30\% and 50\% in inactive and highly active groups, respectively, with an alpha error of $50 \%$, power of $80 \%$; 91 individuals in each quartile, or a total of 364 volunteers would be needed. Our final sample was composed of 14 physical educators (3.3\%), 55 nurses (12.9\%), 127 students (29.8\%), 106 cardiologists (24.9\%), 55 non-cardiologist physicians (12.9\%), 2 dietitians $(0.5 \%)$ and $67(15.7 \%)$ other health care professionals.

A multivariate model (logistic regression) was used, with a correct answer to the question about physical activity recommendations as dependent variable, and including variables with alpha errors lower than 5\% in the univariate analysis. Continuous variables were expressed as mean and standard deviation or median and interquartile range, and analyzed using the Student's t test or the Mann-Whitney U test, depending on normality of data distribution. Categorical variables were expressed as percentage and analyzed by the chi-square test or Fisher's exact test. Statistical analysis was performed using the SPSS software for Windows, version 22.0. The level of significance was set at 5\%. The study was approved by the ethics committee of Casa de Saúde São José (CAAE 71943817.4.000.5664; approval number 2.404.247), and conducted according to the Helsinki Declaration.

\section{Results}

Of a total of 2,652 attendees of the conference, 426 $(16.1 \%)$ were interviewed; $45.5 \%$ of these were men, median age of 31 [18] years. One hundred sixty-one $(37.8 \%)$ were physicians, 106 cardiologists $(24.5 \%$ of participants and $65.8 \%$ of physicians).

Of the 426 volunteers, $190(44.6 \%)$ answered the question about physical exercise correctly; $38.1 \%$ of them were non-physicians, $52.7 \%$ were non-cardiologist physicians and $56.6 \%$ were cardiologists $(\mathrm{p}=0.002)$.

With respect to physical activity level, median PA-I was $3.75(4.62)(p<0.001) ; 21.8 \%$ of them were classified as inactive, $15 \%$ lightly active, $34.7 \%$ moderately active and $28.4 \%$ highly active $(\mathrm{p}=0.003)$. Characteristics of the study population are described in Table 1.

Median $\mathrm{VO}_{2}$ max was 40.3 (8.54) mL/kg.min and aerobic conditioning measured by percentage of $\mathrm{VO}_{2^{\prime}}$ predicted by age and sex was 89.4 (1.2)\% (median). Sixty-nine volunteers $(16.2 \%)$ showed poor abnormal aerobic conditioning $(<80 \%$ of predicted). Among
Table 1 - Characteristics of the study population $(n=426)$

\section{Variables}

Age (mean and standard deviation)

31 (18) years

Age range, n (\%)

21-30 years

$206(48.4 \%)$

31-40 years

$105(24.6 \%)$

41-50 years

$56(13.1 \%)$

51-60 years

$41(9.6 \%)$

61-70 years

$12(2.8 \%)$

$>70$ years

$6(1.4 \%)$

Sex, n (\%)

Female

$232(54.5 \%)$

Male

$194(45.5 \%)$

Occupation, n (\%)

Physical educator

$14(3.3 \%)$

Nurse

$55(12.9 \%)$

Student

$127(29.8 \%)$

Cardiologist physician

$106(24.9 \%)$

Non-cardiologist physician

$55(12.9 \%)$

Dietitian

$2(0.5 \%)$

Others

$67(15.7 \%)$

Body mass index $\left(\mathrm{kg} / \mathrm{m}^{2}\right)$ (mean and standard deviation)

$24.7(5.1)$

Body mass index classification (\%)

Underweight

$15(3.5 \%)$

Normal weight

$213(50 \%)$

Overweight

$149(35 \%)$

Class I obesity

$32(7.5 \%)$

Class I obesity

$13(3.1 \%)$

Class I obesity

$4(0.9 \%)$

Heart rate (bpm) (mean and standard deviation)

inactive participants, $30.1 \%$ answered the question about physical activity correctly, whereas $52.9 \%$ of highly active answered it correctly $(\mathrm{p}<0.001)$ (Figure 1). PA-I was 2.37 (3.75) and 3.75 (4.05) in subjects who gave correct and incorrect answers, respectively $(p<0.001)$. Individuals who answered the question 


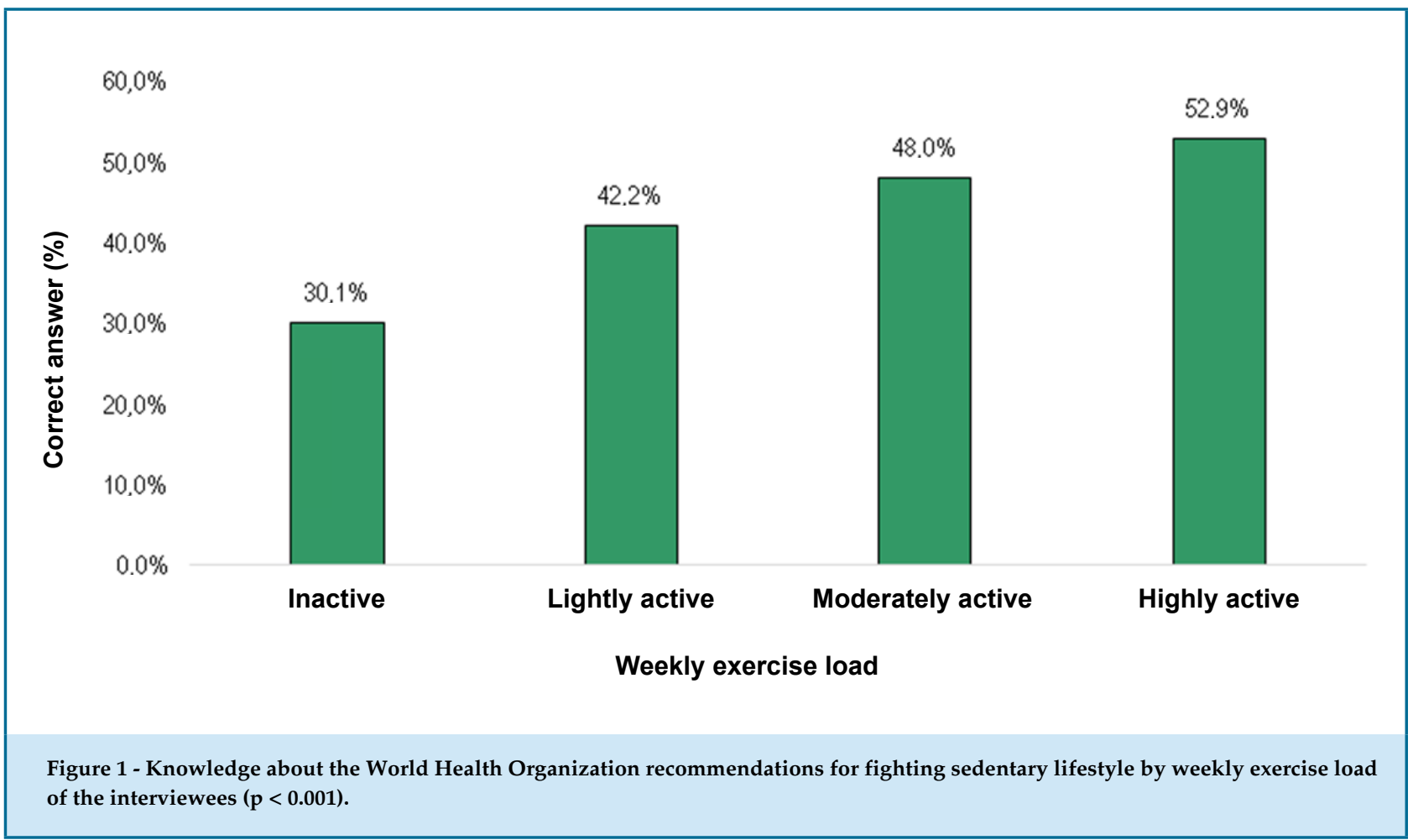

about physical exercise correctly showed a higher frequency, more intense and of longer duration exercise (Table 2). Percentage of $\mathrm{VO}_{2}$ predicted by age was 88.3 $(1.2) \%$ and $91(1.1) \%$, for those who gave wrong and correct answer to the question, respectively $(p=0.009)$, but no difference was found in the presence of poor aerobic conditioning between these individuals.

In the multivariate analysis, high intensity physical exercise was the main independent predictor of a correct answer to the question about physical activity $(\mathrm{OR}=2.25 ; 95 \% \mathrm{CI} 1.238-4.089)$. Being moderately active $(\mathrm{OR}=1.93 ; 95 \%$ IC $1.105-3.39)$, being a cardiologist $(\mathrm{OR}=2.01 ; 95 \%$ CI $1.243-3.267)$ and being a noncardiologist physician (OR $=1.82 ; 95 \%$ CI $1.009-3.300)$ were also associated with the outcome (Table 3).

In a second model including the same variables, we observed an interaction between occupation and physical activity; being a physically active cardiologist physician increased the likelihood of knowing the WHO recommendation for physical activity by 4.37 times (95\% CI 2.08-9.17).

\section{Discussion}

Physically active health care professionals not only take care of their own health, but can also motivate patients to exercise. In our study, $30.4 \%$ of physicians and $38.2 \%$ of cardiologists were inactive or lightly active. Our findings showed that the knowledge about WHO recommendations on the weekly practice of physical exercise among physicians $(55.2 \%)$ were similar to those reported by Patra et al., ${ }^{6}$ among physicians in India $(51.2 \%)$. There was a linear relationship between physical activity level, measured by the domains of exercise intensity, frequency and duration, and the knowledge about exercise. The practice of high-intensity exercise increased, by more than twice, the likelihood of knowing WHO recommendations, in addition to be the best predictor of knowledge among the variables. In addition, the interaction of being a cardiologist with the practice of high-intensity exercise potentiated this effect, and increased by more than four times the likelihood of knowing the WHO recommendations on exercise.

Clinical studies that evaluated how physicians take care of their own health have shown conflicting results. Frank et al., ${ }^{13}$ in an epidemiological study involving four million individuals in the USA, showed that male physicians were older when they died (73 years) than lawyers (72 years) and the general population (70 years). Other studies also conducted with North American populations, showed healthier life style among physicians and other health care professionals 
Table 2 - Characteristics of participants by subgroups of individuals who gave a correct answer and a wrong answer to the question about the World Health Organization recommendation on exercise

\begin{tabular}{|c|c|c|c|c|}
\hline & Total & Wrong answer & Correct answer & p value \\
\hline Population (n) & 426 & 236 & 190 & \\
\hline$(\%)$ & & $55.4 \%$ & $44.6 \%$ & \\
\hline Age (years) & $31(18)$ & $30(17.8)$ & $32.5(18)$ & 0.373 \\
\hline \multicolumn{5}{|l|}{ Sex, $\mathrm{n}(\%)$} \\
\hline Male & $194(45.5)$ & $100(51.5)$ & $94(48.5)$ & 0.144 \\
\hline \multicolumn{5}{|l|}{ Occupation n $(\%)$} \\
\hline Non-physicians & $265(62.2)$ & $164(61.9)$ & $101(38.1)$ & \multirow{3}{*}{0.002} \\
\hline Non-cardiologist physicians & $55(12.9)$ & $26(47.3)$ & $29(52.7)$ & \\
\hline Cardiologist physicians & $106(24.9)$ & $46(43.4)$ & $60(56.6)$ & \\
\hline \multicolumn{5}{|l|}{ Frequency of weekly exercise, n(\%) } \\
\hline Never & $94(22.1)$ & $65(69.1)$ & $29(30.9)$ & \multirow{5}{*}{0.017} \\
\hline$<$ Once a week & $35(8.2)$ & $20(57.1)$ & $15(42.9)$ & \\
\hline Once a week & $36(8.5)$ & $22(61.1)$ & $14(38.9)$ & \\
\hline Two-three times/week & $191(44.8)$ & $97(50.8)$ & $94(49.2)$ & \\
\hline Almost every day & $70(16.4)$ & $32(45.7)$ & $38(54.3)$ & \\
\hline \multicolumn{5}{|l|}{ Exercise intensity n(\%) } \\
\hline Without sweating or breathing fast & $47(11)$ & $33(70.2)$ & $14(29.8)$ & \multirow{3}{*}{$<0.001$} \\
\hline Sweating and breathing fast & $240(56.3)$ & $115(47.9)$ & $125(52.1)$ & \\
\hline Until exhaustion & $46(10.8)$ & $23(50)$ & $23(50)$ & \\
\hline \multicolumn{5}{|l|}{ Exercise duration $\mathrm{n}(\%)$} \\
\hline Less than 15 minutes & $5(1.2)$ & $2(40)$ & $3(60)$ & \multirow{4}{*}{0.034} \\
\hline Between 15 and 30 minutes & $31(7.3)$ & $16(51.6)$ & $15(48.4)$ & \\
\hline Between 30 e 60 minutes & $206(48.4)$ & $107(51.9)$ & $99(48.1)$ & \\
\hline More than 60 minutes & $91(21.4)$ & $46(50.5)$ & 45 (49.5) & \\
\hline Heart rate $(\mathrm{bpm})$ & $79.5(20)$ & $80.5(20.8)$ & $78.5(21)$ & 0.385 \\
\hline PA-I & $3.75(4.62)$ & $2.37(3.75)$ & $3.75(4.05)$ & $<0.001$ \\
\hline Body mass index $\left(\mathrm{kg} / \mathrm{m}^{2}\right)$ & & & & 0.204 \\
\hline \multicolumn{5}{|l|}{ PA-I Classification n(\%) } \\
\hline Inactive & $93(21.8)$ & $65(69.9)$ & $28(30.1)$ & \multirow{4}{*}{0.003} \\
\hline Lightly active & $64(15)$ & $37(57.8)$ & $27(42.2)$ & \\
\hline Moderately active & $148(34.7)$ & $77(52)$ & $71(48)$ & \\
\hline Highly active & $121(28.4)$ & $57(47.1)$ & $64(52.9)$ & \\
\hline $\mathrm{VO}_{2} \max (\mathrm{mL} / \mathrm{kg} / \mathrm{min})$ & $40.03(8.54)$ & $39.35(9.01)$ & $41.2(7.04)$ & 0.03 \\
\hline Predicted $\% \mathrm{VO}_{2}$ & $89.4(1.2)$ & $88.3(1.2)$ & $91(1.1)$ & 0.009 \\
\hline Poor aerobic conditioning (\%) & $69(16.2)$ & 39 (16.5) & $30(15.8)$ & 0.838 \\
\hline
\end{tabular}


Table 3 - Multivariate analysis

\begin{tabular}{lcc}
\hline & OR & $\begin{array}{c}95 \% \text { confidence } \\
\text { interval }\end{array}$ \\
\hline $\begin{array}{l}\text { Predicted } \% \mathrm{VO}_{2} \\
\text { Occupation } \mathrm{n}(\%)\end{array}$ & 1.02 & $(0.979-1.046)$ \\
$\quad$ Non-physicians & 1.00 & \\
$\quad$ Cardiologist physicians & 2.01 & $(1.243-3.267)$ \\
$\quad$ Non-cardiologist physicians & 1.82 & $(1.009-3.300)$ \\
PA-I Classification n $(\%)$ & 1.00 & \\
Inactive & 1.62 & $(0.76-3.014)$ \\
Lightly active & 1.93 & $(1.105-3.39)$ \\
Moderately active & 2.25 & $(1.238-4.089)$ \\
\hline
\end{tabular}

compared with the general population. ${ }^{14,15}$ In contrast, Borgan et al.,16 detected unfavorable lifestyle habits (70\% were physically inactive and 33\% obese) among physicians in Bahrai. Aasland et al., ${ }^{17}$ reported higher mortality in physicians than other higher education professionals in Norway.

The association between the adoption of healthy lifestyle habits by physicians and the quality of their advice on prevention strategies is very well established. Bleich et al., ${ }^{18}$ showed that non-obese physicians are more likely to record an obesity diagnosis in the medical chart, and to initiate weight loss counseling to their patients as compared with obese physicians. Pipe et al., ${ }^{19}$ interviewed 4,473 doctors and found that smoking physicians were less likely to initiate smoking cessation interventions than non-smoking physicians. Abramsonet al., ${ }^{20}$ evaluated 298 doctors of several specialties and found that those who practiced aerobic exercise had 5.72 (95\% CI 2.41-13.54) greater chance to recommend aerobic exercise, and those who practiced resistance exercise were 4.55 times more likely to counsel their patients on the benefits of these exercise (95\% CI 2.61-7.91) than those who did not exercise.

A regular practice of exercise can be difficult to be maintained in the beginning of the medical course, which coincides with the end of adolescence or initial of adult life. During more than ten years of medical school, including both undergraduate and residency programs, the lack of time and mainly the lack of encouragement to be physically active, contribute to a sedentary lifestyle and other unhealthy habits among doctors. This leads to underestimation of the practice of physical exercise as a strategy of disease prevention and health promotion for doctors and their patients.

Dacey et al., ${ }^{21}$ in a detailed systematic review on physical activity counseling education in medical schools highlighted that the first step to promote more effective physician practices on physical activity counseling is to address students' physical activity behavior. To our knowledge, few medical schools include the discipline of physical education in their programs, and when included, it is not given due attention and importance, reflecting bad quality university sports programs in terms of organization and structure, and inadequate for education, leisure and health promotion required by young students. As a result, medical professionals are less healthy and less likely to address physical inactivity of their patients as a health problem. Besides, this academic program model ultimately has a negative impact on society, as it promotes a poor interaction between physicians and physical educators, who in turn have a very important role in the fight against a sedentary lifestyle.

Physical inactivity is an important public health problem in the world that has been target of many strategies supported by government fund $\mathrm{s}^{22-24}$ and foundations. ${ }^{25-26}$ Physicians play a key and, so far, irreplaceable role in this lifestyle changing process, and in this context, a medical visit turns to be an excellent opportunity to achieve that. In Brazil, $54.7 \%$ of the population, mostly women and older subjects, reported having been to a medical appointment in the last 12 months, and $71.2 \%$ of the population seek healthcare services regularly.

Kreuter et al., ${ }^{27}$ showed that patients who received physician advice on health promotion before receiving printed materials on the same theme were $35 \%$ to $55 \%$ more likely to quit smoking, change dietary habits, or begin to exercise. The present study, corroborating previous studies, show that physicians with healthy lifestyle habits have greater ability and/or knowledge to motivate patients to adopt healthy habits. ${ }^{28}$

A cross sectional study conducted during a medical congress aiming to evaluate knowledge of participants is subject to selection bias, since it is expected that the level of knowledge of these participants, involved in continued education, is greater than of professionals 
that are out of this academic environment. Although heart rate measurements were performed at the end of the interview sessions, they were not taken after a tenminute resting period, as in previous studies. This may have resulted in higher heart rates, and underestimation of aerobic conditioning of participants. Nevertheless, all measurements were performed very carefully in attempt to obtain the lowest heart rate values. Also, one cannot assure that the fact of being aware of the WHO recommendations on physical exercise actually leads to effective counseling of patients in this sense by the doctors. It is worth mentioning that our volunteers were not asked about when or how often they received medical advice on physical activity.

The fact that both body weight and height were self-reported was another limitation of our study. A previous study involving 11,284 adults aged between 20 and 74 years from the second National Health and Nutrition Examination Survey of 1976-1980 evaluated errors in self-reported weight and height. The authors found that, although both were reported, on the average, with small errors, self-reported weight and height were not reliable in important population subgroups. Errors in self-reports were directly related to an overweight status - tendency and lack of reliability in self-report is directly proportional to the magnitude of overweight. Errors in selfreported weight were greater in overweight women than in overweight men. Race, age, and end-digit preference were auxiliary predictors of error in weight reporting. Errors in self-reporting height were related to a person's age--bias and lack of reliability in selfreporting increased directly with age after the age of 45 years. Overweight status was also a predictor of reporting error in height. ${ }^{29}$

A physically active medical community could not only give due consideration to the problem of physical inactivity, but also gain credibility by using a powerful argument during consultations: "Do what I say, do what I do!" In order to form physically active physicians, the first step could be to analyze how the topic "physical activity" has been addressed in the universities, which should take care of their students, by providing them with adequate infrastructure and logistics for the development of university sports programs. In addition, Medical Councils could assume a role in motivating physicians to be physically active throughout their professional careers.

\section{Conclusion}

In this study, the knowledge about the WHO recommendations on weekly exercise was greater among more physically active physicians. Cardiologists were slightly more likely to know about these recommendations than non-cardiologists, and being a physically active cardiologist was an independent predictor of knowledge.

This study was funded by the Human Performance Laboratory of the Casa de Saúde São José.

\section{Acknowledgements}

We thank the former President (2016-2017) of Rio de Janeiro Society of Cardiology, Prof. Dr. Ricardo Mourilhe Rocha, for his unconditional support for this study.

\section{Author contributions}

Conception and design of the research: Meira DT, Gonçalves LG, Araújo LH, Gasparini M, Cunha BS, Monteiro A, Heringer M, Prado C, Volschan A, Silva FB. Acquisition of data: Meira DT, Gonçalves LG, Araújo LH, Gasparini M, Cunha BS, Monteiro A, Heringer M, Prado C, Volschan A, Silva FB. Analysis and interpretation of the data: Meira DT, Gonçalves LG, Araújo LH, Gasparini M, Cunha BS, Monteiro A, Heringer M, Prado C, Volschan A, Silva FB. Statistical analysis: Meira DT, Gonçalves LG, Araújo LH, Gasparini M, Cunha BS, Monteiro A, Heringer M, Prado C, Volschan A, Silva FB. Obtaining financing: Meira DT, Gonçalves LG, Araújo LH, Gasparini M, Cunha BS, Monteiro A, Heringer M, Prado C, Volschan A, Silva FB. Writing of the manuscript: Meira DT, Gonçalves LG, Araújo LH, Gasparini M, Cunha BS, Monteiro A, Heringer M, Prado C, Volschan A, Silva FB. Critical revision of the manuscript for intellectual content: Meira DT, Gonçalves LG, Araújo LH, Gasparini M, Cunha BS, Monteiro A, Heringer M, Prado C, Volschan A, Silva FB.

\section{Potential Conflict of Interest}

No potential conflict of interest relevant to this article was reported.

\section{Sources of Funding}

This study was funded by Laboratório de Performance Humana (LPH) 


\section{Study Association}

This study is not associated with any thesis or dissertation work.

\section{Ethics approval and consent to participate}

This study was approved by the Ethics Committee of the Associação Congregação de Santa Catarina under

\section{References}

1. Lee I-M, Shiroma EJ, Lobelo F, Puska P, Blair SN, Katzmarzyk PT. Impact of physical inactivity on the world's major non-communicable diseases. Lancet. 2012;380(9838):219-29.

2. Andersen LB, Mota J, Di Pietro L. Update on the global pandemic of physical inactivity. Lancet .2016;388(10051):1255-6

3. Ding D, Lawson KD, Kolbe-Alexander TL, Finkelstein EA, Katzmarzyk $\mathrm{PT}$, van Mechelen $\mathrm{W}$, et al. The economic burden of physical inactivity: a global analysis of major non-communicable diseases. Lancet [Internet]. 2016;388(10051):1311-24.

4. Brasil. Ministério da Saúde. VIGITEL BRASIL 2016. Brasilia; 2016.

5. Instituto Brasileiro de Geografia e Estatística: IBGE. Práticas de esporte e atividade física. Rio de Janeiro; 2015.

6. Patra L, Mini GK, Mathews E, Thankappan KR. Doctors' self-reported physical activity, their counselling practices and their correlates in urban Trivandrum, South India: should a full-service doctor be a physically active doctor? Br J Sport Med. 2015;49:413-6.

7. Berra K, Rippe J, Manson JE. Making physical activity counseling a priority in clinical practice: the time for action is now. Jama. 2015;314(24):2617-8.

8. World Health Organization.(WHO) Physical activity. Geneva;2017.

9. Colberg SR, Sigal RJ, Yardley JE, Riddell MC, Dunstan DW, Dempsey PC, et al. Physical activity / exercise and diabetes: A position statement of the American Diabetes Association. Diabetes Care. 2016;39(11):2065-79.

10. Aspenes ST,Nauman J,Nilsen TIL,Vatten LJ, Wisloff U. Physical activity as a long-term predictor of peak oxygen uptake. Med Sci Sport Exerc.2011;43(9):675-9

11. Martens NB, Vatten LJ, Nauman J, Janszky I, Wisloff U. The world fitness study:estimating VO2max to predict mortality comment by trine karlsen, Med Sci Sports Exerc. 2011;3(11):2024-30.

12. Kurtze N, Rangul V, Hustvedt B-E, Flanders WD. Reliability and validity of self-reported physical activity in the Nord-Trøndelag Health Study: HUNT 1. Scand J Public Health. 2008;36(1):52-61.

13. Frank E, Biola H, Burnett CA. Mortality rates and causes among U.S. physicians. Am J Prev Med. 2000;19(3):155-9.

14. Hughes PH, Brandenburg N, Baldwin DC, Storr CL, Williams KM, Anthony JC, et al. Prevalence of substance use among US physicians. JAMA.1992;267(17):2333-9.

15. Nelson DE, Giovino GA, Emont SL, Brackbill R, Cameron LL, Peddicord $\mathrm{J}$, et al. Trends in cigarette smoking among US physicians and nurses. JAMA. 1994;271(16):1273-5.

16. Borgan SM, Jassim GA, Marhoon ZA, Ibrahim MH. The lifestyle habits and wellbeing of physicians in Bahrain: A cross-sectional study. BMC Public Health. 2015;15(1):1-7. the protocol number 2.404.247. All the procedures in this study were in accordance with the 1975 Helsinki Declaration, updated in 2013. Informed consent was obtained from all participants included in the study.
17. Aasland OG, Hem E, Haldorsen T, Ekeberg Ø. Mortality among Norwegian doctors 1960-2000. BMC Public Health . 2011;11(1):173.

18. Bleich SN, Bennett WL, Gudzune KA, Cooper LA. Impact of physician BMI on obesity care and beliefs. Obesity .2012;20(5):999-1005

19. Pipe A, Sorensen M, Reid R. Physician smoking status, attitudes toward smoking, and cessation advice to patients: An international survey. Patient Educ Couns. 2009;74(1):118-23.

20. Abramson S, Stein J, Schaufele M, Frates E, Rogan S. Personal exercise habits and counseling practices of primary care physicians: a national survey. Clin J Sport Med. 2000;10(1):40-8.

21. Dacey ML, Kennedy MA, Polak R, Phillips EM. Physical activity counseling in medical school education: a systematic review. Med Educ Online. 2014;19(4):24325.

22. Forman DE, Arena R, Boxer R, Dolansky MA, Eng JJ, Fleg JL, et al. Prioritizing functional capacity as a principal end point for therapies oriented to older adults with cardiovascular disease: A scientific statement for healthcare professionals from the American Heart Association. Circulation. 2017;135(16):e894-918.

23. Ross R, Blair SN, Arena R, Church TS, Després JP, Franklin BA, et al. Importance of assessing cardiorespiratory fitness in clinical practice: a case for fitness as a clinical vital sign: a scientific statement from the American Heart Association. Vol. 134, Circulation. 2016. 653-99 p.

24. Joy EL, Blair SN, McBride P, Sallis R. Physical activity counselling in sports medicine: a call to action. Br J Sports Med. 2013;47(1):49-53.

25. Brawner CA, Al-Mallah MH, Ehrman JK, Qureshi WT, Schairer JR, Blaha MJ, et al. Change in cardiorespiratory fitness is inversely related to mortality among men and women: Data from the Henry Ford exercise testing (FIT) project. Circulation. 2015;132(Suppl 3):15613

26. Shaya GE, Al-Mallah MH, Hung RK, Nasir K, Blumenthal RS, Ehrman JK, et al. High exercise capacity attenuates the risk of early mortality after a first myocardial infarction: The Henry Ford Exercise Testing (FIT) Project. Mayo Clin Proc. 2016;91(2):129-39.

27. Kreuter MW. How does physician advice influence patient behavior?: Evidence for a Priming Effect. Arch Fam Med. 2000;9(5):426-33.

28. Frank E, Breyan J, Elon L. Physician disclosure of healthy personal behaviors improves credibility and ability to motivate. Arch Fam Med [Internet]. 2000;9(3):287-90.

29 Rowland ML. Self-reported weight and height. Am J Clin Nutr.; 52(6): 1125-33. 